\title{
Variants in congenital hypogonadotrophic hypogonadism genes identified in an Indonesian cohort of 46,XY under-virilised boys
}

Katie L. Ayers ${ }^{1,2}$, Aurore Bouty ${ }^{1,3}$, Gorjana Robevska ${ }^{1}$, Jocelyn A. van den Bergen ${ }^{1}$, Achmad Zulfa Juniarto ${ }^{4}$, Nurin Aisyiyah Listyasari ${ }^{4}$, Andrew H. Sinclair ${ }^{1,2+}$ and Sultana M. H. Faradz ${ }^{4^{*}+}$

\begin{abstract}
Background: Congenital hypogonadotrophic hypogonadism $(\mathrm{CHH})$ and Kallmann syndrome (KS) are caused by disruption to the hypothalamic-pituitary-gonadal (H-P-G) axis. In particular, reduced production, secretion or action of gonadotrophin-releasing hormone $(\mathrm{GnRH})$ is often responsible. Various genes, many of which play a role in the development and function of the GnRH neurons, have been implicated in these disorders. Clinically, CHH and KS are heterogeneous; however, in 46,XY patients, they can be characterised by under-virilisation phenotypes such as cryptorchidism and micropenis or delayed puberty. In rare cases, hypospadias may also be present.
\end{abstract}

Results: Here, we describe genetic mutational analysis of $\mathrm{CHH}$ genes in Indonesian $46, \mathrm{XY}$ disorder of sex development patients with under-virilisation. We present 11 male patients with varying degrees of under-virilisation who have rare variants in known $\mathrm{CHH}$ genes. Interestingly, many of these patients had hypospadias.

Conclusions: We postulate that variants in CHH genes, in particular PROKR2, PROK2, WDR11 and FGFR1 with CHD7, may contribute to under-virilisation phenotypes including hypospadias in Indonesia.

Keywords: Congenital hypogonadotrophic hypogonadism, Under-virilisation, Hypospadias, Targeted gene sequencing, Disorder of sex development

\section{Background}

Proper function of the hypothalamic-pituitary-gonadal (H-P-G) axis is essential for the development of the reproductive system. Gonadotrophin-releasing hormone $(\mathrm{GnRH})$, secreted by the hypothalamus, stimulates the biosynthesis and the release of gonadotrophins from the anterior pituitary gland. These gonadotrophins (luteinising hormone (LH) and follicle-stimulating hormone $(\mathrm{FSH})$ ) both play distinct roles in the gonads during embryonic development. In males, FSH stimulates the proliferation of immature Sertoli cells and spermatogonia [1]. FSH also stimulates the secretion of inhibin, which

\footnotetext{
*Correspondence: sultanafaradz@gmail.com

${ }^{\dagger}$ Equal contributors

${ }^{4}$ Division of Human Genetics, Centre for Biomedical Research, Faculty of Medicine, Diponegoro University (FMDU), JL. Prof. H. Soedarto, SH,

Tembalang, Semarang 50275, Central Java, Indonesia

Full list of author information is available at the end of the article
}

acts in a negative feedback loop directly to the anterior pituitary. LH stimulates the production and secretion of testosterone from the Leydig cells, which is thought to occur through the LH receptor after 10 weeks post conception [2]. Disruption to the H-P-G axis (through deficient production, secretion or action of the gonadotrophins) can result in hypogonadotrophic hypogonadism (HH). While this can be associated with additional anomalies or syndromes such as Dandy-Walker syndrome, Gorden Holmes syndrome and CHARGE [3], when observed alone, it is termed congenital or idiopathic $\mathrm{HH}(\mathrm{CHH})$ (OMIM 146110). CHH can be coupled with a decreased or absent sense of smell due to the abnormal migration of the GnRH neurons [4,5]. The co-occurrence of $\mathrm{CHH}$ with anosmia is termed Kallmann syndrome (KS (OMIM 308700, 147950, 244200, 610628, 612370 and 612702)). 
Estimates of the prevalence of $\mathrm{CHH}$ range between 1 and 10 in 100,000 live births, with approximately two thirds of cases arising from KS [6]. $\mathrm{CHH}$ in 46, XY males can cause a reduced level of circulating androgens due to hypogonadism. Isolated or apparently isolated $\mathrm{CHH}$ (i.e. in a patient with KS who does not complain of an absent or diminished sense of smell) is most commonly diagnosed in teenagers or young men who present with pubertal failure. During foetal development, testosterone is responsible for virilisation of the reproductive tract and dihydrotestosterone (DHT), a highly potent derivative of testosterone, drives differentiation of the external genitalia. The appearance of clinical characteristics depends on when $\mathrm{HH}$ begins. When GnRH deficiency occurs in the late foetal or early neonatal periods, a significant decrease in androgens can lead to some $\mathrm{CHH}$ patients being diagnosed postnatally with under-virilisation phenotypes such as cryptorchidism, micropenis [7] and, in some rare cases, hypospadias [8]. Patients also typically showed delayed or absent puberty including minimal virilisation, low libido, lack of sexual function and a reduced or absent growth spurt [3]. In addition to the physical anomalies, physiological impairments have also been reported such as low self-esteem, distorted body image and, in some cases, problems in sexual identity $[9,10]$. Finally, $\mathrm{CHH}$ may be diagnosed following adolescence, later in life when infertility is a concern. Given these complex and significant physical and psychological implications, early diagnosis and treatment of $\mathrm{CHH}$ is essential. Clinically, $\mathrm{CHH}$ can phenocopy partial androgen insensitivity syndrome (PAIS) or other disorders of sex development (DSDs) in which a reduction of testosterone during development can cause reduced virilisation. If blood hormone testing is not routinely carried out, these patients may be misdiagnosed and clinical management may differ.

Genetically, $\mathrm{CHH}$ is highly complex. More than 30 genes have been implicated in $\mathrm{CHH}$ and/or KS including nine genes that cause an overlapping syndrome [3]. To complicate matters, a large degree of variability in inheritance, penetrance and expressivity is seen in $\mathrm{CHH}$ and an increasing body of evidence suggests that this disorder can be caused by variants in more than one gene (oligogenicity) [11, 12]. Variants in known $\mathrm{CHH}$ genes currently account for only $50 \%$ of $\mathrm{CHH}$ cases [13] meaning that more genes are yet to be found. Here, we present genetic mutational analysis of $\mathrm{CHH}$ genes in Indonesian 46,XY patients presenting with under-virilisation phenotypes.

\section{Materials and methods}

\section{Clinical data}

Patients with 46,XY DSD were referred to the Center for Biomedical Research, Faculty of Medicine, Diponegoro University (FMDU), Semarang, Indonesia. The medical ethics committee of the Dr. Kariadi Hospital/FMDU approved this study, and informed consent was obtained from all participants, as well as their parents or guardians, prior to their participation in this study. Following informed consent, a detailed interview was performed at recruitment and data concerning medical history, age of initial presentation, sex of rearing, family history (relatives with a genital disorder) and consanguinity were collected. Patients were clinically evaluated by a trained andrologist; a detailed description of the external genitalia was obtained and, in many cases, images taken. A blood sample was obtained for karyotyping, hormonal analysis and DNA extraction. Referral and data collection took place between 2004 and 2010. Eighty-eight of these patients have been described previously [14]. A total of 47 males with 46,XY under-virilisation phenotypes (including uni- or bilateral cryptorchidism, hypospadias, bifid scrotum, micropenis and, in some cases, severe hypospadias) were included in this study. Hormone analysis was carried out for some patients including base level $\mathrm{LH}$ and FSH and testosterone (T). Reference levels for FSH and LH are based on paediatric measurements depending on age [15]. In some cases, $T$ levels were also measured following Leydig cell stimulation by human chorionic gonadotrophin (hCG). For more details on blood hormone analysis, see [14].

\section{Gene panel sequencing}

Genomic DNA was obtained from peripheral EDTAblood samples using the salting out method [16]. The DNA underwent quality control at the Murdoch Childrens Research Institute (MCRI), Melbourne, Australia. Total genomic DNA was sequenced using a targeted panel (Haloplex, Agilent) that covers 64 diagnostic DSD genes [17]. This included 19 genes implicated in $\mathrm{CHH}$ (CHD7, GNRH1, GNRHR, HESX1, LEP, PROKR2, PROP1, TAC3, FGFR1, KAL1, LHX3, FGF8, PROK2, KISS1R, WDR11, SPRY4, FSHB, CGA, SOX10). Library preparation and sequencing were carried out as detailed in [17]. Raw data was analysed using a modified pipeline created at MCRI-C-pipe, which calls variants and provides data on frequency and pathogenicity [18].

Following C-pipe analysis, variants were checked for quality and depth and were filtered for those less than $1 \%$ minor allele frequency (MAF) in both the ESP6500 and 1000 genome project. As non-affected controls from Indonesia were not included, variants that were found very frequently in our screen (greater than $5 \%$ of total samples run) were also discounted. We manually check variant frequency in EVS and extracted ExAC data on frequency in Asia (South Asia and East Asia). Variants were checked for previous implication in human disease via ClinVAR and HMGD. Predicted pathogenicity of each variant was analysed using a range of up-to-date in silico prediction tools (SIFT, PolyPhen-2, LRT and 
MutationTaster). Effects on protein structure and function were predicted using the HOPE tool [19].

\section{Results \\ Patient cohort}

All forty-seven 46,XY DSD patients from Indonesia were first analysed for mutations in DSD genes that cause androgen insensitivity or reduced testosterone production (e.g. androgen receptor (AR), SRD5A2, HSD17B3). Rare and damaging mutations in these genes were found in 19 patients [17] of the 47 . The other 28 did not have a causative variant identified. These patients ranged in age from newborn to 14 years old, with a variety of 46,XY DSD phenotypes including hypospadias, bifid scrotum, cryptorchidism/undescended testis, microtestis and micropenis. All patients identify as male. Many have undergone hypospadias repair. The phenotypes of the eleven patients with a $\mathrm{CHH}$ variant are shown in Table 1 , and representative images are shown in Fig. 1.

The hallmarks of $\mathrm{CHH}$ can include low levels of testosterone (due to hypogonadism), which can often be increased by hCG stimulation. Indeed, we found that all of the patients tested showed moderate to high increases in testosterone after hCG stimulation (Table 1). In addition, low levels of LH and FSH are often indicative of $\mathrm{CHH}$; however, the natural levels of these hormones are low during childhood. Indeed, most patients were between mini-puberty and puberty when FSH/LH levels are expected to be low $(<0.1-4 \mathrm{IU} / \mathrm{l}$ for $\mathrm{LH}$ and $<0.1-8 \mathrm{IU} /$ 1 for FSH). For all patients of this age, assayed LH and FSH levels were within the normal range. Patient 169 , who was 14 at the time, had an LH measurement of $2.7 \mathrm{IU} / \mathrm{l}$, which is within normal range, but an FSH of 9.24 IU/I, which is considered slightly elevated. Patient 147 was within minipuberty at the time of measurement and subsequently had an elevated LH level of 10.8 and FSH of 6.23. This may suggest that secretion of these gonadotrophins is not inhibited in this patient. Patient 143 did not have hormonal analysis.

\section{$\mathrm{CHH}$ genetic variants}

The remaining 28 patients were then analysed for mutations in the exonic regions of $\mathrm{CHH}$ genes as previously detailed in [17]. Eleven patients had one or more rare variants $(<1 \%$ MAF in g1000 and ESP6500) in a $\mathrm{CHH}$ gene (Table 2). In total, we found 14 variants in $\mathrm{CHH}$ genes in these patients. The variants are described below.

\section{PROKR2}

Four patients had variants in the PROKR2 gene. Two patients (173 and 143) had the same variant-PROKR2:c.C563T:pS188L (Table 2). This variant has not been found in our DSD panel previously (in over 300
DSD patients; see [17]) but has a total allele frequency of $1.65 \mathrm{e}-05$ in ExAC (although it has not been recorded in SA or EA). This change has been recorded to be likely pathogenic (ClinVar) [20, 21] (Table 2). Previous functional analysis has shown this variant has a strong defect in G-protein coupling [21]. The two patients with this variant (patients 173, 143) had under-virilisation phenotypes including micropenis, scrotal hypospadias and cryptorchidism (Fig. 1, Table 1). Interestingly, one of these patients also had additional anomalies. Patient 173 had spina bifida, incontinence and suspected intellectual disability-suggesting additional genetic or environmental contributors (Table 1). Indeed, the mother of this patient had a suspected folic acid deficiency during pregnancy.

Two other patients had heterozygous missense variants in the PROKR2 gene (Table 2). c.G991A:p.V331M was found in patient 159 who has perineal hypospadias and unilateral cryptorchidism (Fig. 1, Table 1). This variant (rs117106081) has a total frequency in ExAC of 0.0065 (and was greater than 0.01 in both SA and EA). It is not predicted to be damaging in any of the in silico prediction tools and was not highly conserved. Nevertheless, this variant has been previously reported in $\mathrm{CHH} / \mathrm{KS}$ patients, and functional analysis in both publications suggested a reduction in function (in particular a mild G-protein coupling defect) [21-23]. In contrast, another variant c.T1054G:p.W352G was not found in ExAC or EVS and was predicted to be damaging and highly conserved among different species (Table 2 and Fig. 2a). This was found in a patient 171, who has bilateral cryptorchidism and scrotal hypospadias (Fig. 1 and Table 1). In this case, the mutated residue is located on the surface of a domain with unknown function (Fig. 2b). The mutant residue (glycine) is smaller than the wild-type residue and differs in hydrophobicity to the wild-type residue (tryptophan). This may cause a loss of external interactions in particular a loss of hydrophobic interactions with other molecules on the surface of the protein.

From this, we hypothesise that PROKR2 variants, in particular the variant p.S188L, represent a significant cause of under-virilisation including cryptorchidism, micropenis and, in some cases, hypospadias in Indonesian 46,XY DSD patients.

\section{PROK2}

One patient (47) was found to harbour a variant in this gene (PROK2:c.G68A:p.R23H). This missense heterozygous variant was not found in any of the online databases; however, it was not predicted to be pathogenic (Table 2). This patient has a micropenis, scrotal hypospadias and unilateral cryptorchidism (Table 1). The first 27 amino acids of PROK2 are a signal peptide, important 
Table 1 Patient clinical details

\begin{tabular}{|c|c|c|c|c|c|c|c|c|c|c|c|}
\hline \multirow{2}{*}{$\begin{array}{l}\text { Patient } \\
\text { ID }\end{array}$} & \multirow{2}{*}{$\begin{array}{l}\text { Age at initial } \\
\text { appointment }\end{array}$} & \multicolumn{2}{|l|}{ Gender } & \multicolumn{4}{|c|}{ Clinical description } & \multirow{2}{*}{$\begin{array}{l}\text { Associated } \\
\text { malformations }\end{array}$} & \multirow{2}{*}{$\begin{array}{l}\text { Anosmia } \\
\text { reported? }\end{array}$} & \multirow{2}{*}{$\begin{array}{l}\text { hCG } \\
\text { stimulation } \\
\text { test } \\
\text { Increased T? }\end{array}$} & \multirow{2}{*}{$\begin{array}{l}\text { Image } \\
\text { provided? }\end{array}$} \\
\hline & & Genetic & $\begin{array}{l}\text { Sex of } \\
\text { rearing }\end{array}$ & Testes & Scrotum & Micropenis & $\begin{array}{l}\text { Urethral } \\
\text { meatus (type } \\
\text { of hypospadias) }\end{array}$ & & & & \\
\hline 173 & 12 & $46, X Y$ & Male & $\begin{array}{l}\text { Bilaterally } \\
\text { non } \\
\text { palpable }\end{array}$ & Bifid & Yes & Scrotal & Spina bifida & Unknown & Moderate & \\
\hline 143 & 6 & $46, X Y$ & Male & $\begin{array}{l}\text { R, not } \\
\text { palpable } \\
\mathrm{L}, 1 \mathrm{ml}, \\
\text { scrotal }\end{array}$ & Bifid & Yes & Scrotal & & No & & Figure $1 b$ \\
\hline 159 & 2 & $46, X Y$ & Male & $\begin{array}{l}\mathrm{R}, 1 \mathrm{ml} \text {, } \\
\text { scrotal } \\
\mathrm{L} \text {, fetractile }\end{array}$ & Bifid & No & Perineal & & Unknown & & \\
\hline 171 & 4 & $46, X Y$ & Male & $\begin{array}{l}\mathrm{R}, 1-2 \mathrm{ml}, \\
\text { scrotal } \\
\mathrm{L}, 2 \mathrm{ml} \text {, } \\
\text { scrotal }\end{array}$ & Bifid & Yes & Scrotal & & No & Yes & Figure 1a \\
\hline 47 & 3 & $46, X Y$ & $\begin{array}{l}\text { Female, } \\
\text { changed } \\
\text { to male } \\
\text { at } 3 \text { years }\end{array}$ & $\begin{array}{l}\mathrm{R}, 2 \mathrm{ml} \text {, } \\
\text { scrotal } \\
\mathrm{L} \text {, not } \\
\text { palpable }\end{array}$ & Bifid & Yes & Scrotal & & No & Yes & \\
\hline 174 & 3 & $46, X Y$ & Male & $\begin{array}{l}\text { R, not } \\
\text { palpable } \\
\text { L, } 1 \mathrm{ml} \text {, } \\
\text { scrotal }\end{array}$ & Fused & Yes & Penoscrotal & & No & Yes & \\
\hline 164 & 3 & $46, X Y$ & Male & $\begin{array}{l}\text { Bilaterally } \\
2 \text { ml, } \\
\text { scrotal }\end{array}$ & Bifid & No & Penoscrotal & & No & Yes & \\
\hline 163 & 10 & $46, X Y$ & Male & $\begin{array}{l}\text { Bilaterally } \\
3 \mathrm{ml} \\
\text { scrotal }\end{array}$ & Bifid & Yes & Penile & & No & Yes & Figure $1 \mathrm{c}$ \\
\hline 147 & $1 \mathrm{~m}$ & $46, X Y$ & Male & $\begin{array}{l}R \text {, inguinal } \\
L \text {, not } \\
\text { palpable }\end{array}$ & Bifid & No & Scrotal & & No & Yes & \\
\hline 101 & 3 & $46, X Y$ & Male & $\begin{array}{l}\text { Bilaterally } \\
2 \mathrm{ml} \\
\text { scrotal }\end{array}$ & Bifid & Yes & Scrotal & & Unknown & Yes & Figure 1d \\
\hline \multirow[t]{2}{*}{169} & 14 & $46, X Y$ & Male & $\begin{array}{l}\mathrm{R}, 4 \mathrm{ml}, \\
\text { scrotal }\end{array}$ & Bifid & no & Penoscrotal & & No & Yes & \\
\hline & & & & $\begin{array}{l}\mathrm{L}, 6 \mathrm{ml}, \\
\text { scrotal }\end{array}$ & & & & & & & \\
\hline
\end{tabular}

Patient identification number and age at first consultation are shown, as well as sex chromosome complement and gender. A description of anomalies is also included. Response to hCG stimulation is shown. Testosterone reference levels were considered as $0.3-0.5 \mathrm{nmol} / \mathrm{l}$ except for patients 169 , 163 and 8 (where reference was considered $3-6.5 \mathrm{nmol} / \mathrm{l})$

for its secretion. The affected amino acid (arginine at position 23) lies within this region.

\section{WDR11}

Three patients had heterozygous missense variants in WDR11 (Table 2, patients 174, 164, 163). The first of these was one of a pair of twins, who have concordant phenotypes (patient 174, twin not analysed). This variant, WDR11:c.G2409T:p.W803C, was not found in online databases and is predicted to be pathogenic with strong conservation-even down to zebrafish (Table 2,
Fig. 2c). Patient 174 has a micropenis with penoscrotal hypospadias and chordee (Fig. 1, Table 1). The second variant found was WDR11:c.A1352G:p.H451R (Table 2). This variant (rs199920020) has a total frequency of 0.0001 in ExAC but is rare in Asia and was found in a patient with penoscrotal hypospadias and bifid scrotum but no micropenis or cryptorchidism (patient 164, Fig. 1, Table 1). Like the previous variant, this amino acid is highly conserved (Fig. 2c). The third variant (WDR11:c.T1279A:p.L427I) was not previously found in any online databases and was predicted to be 

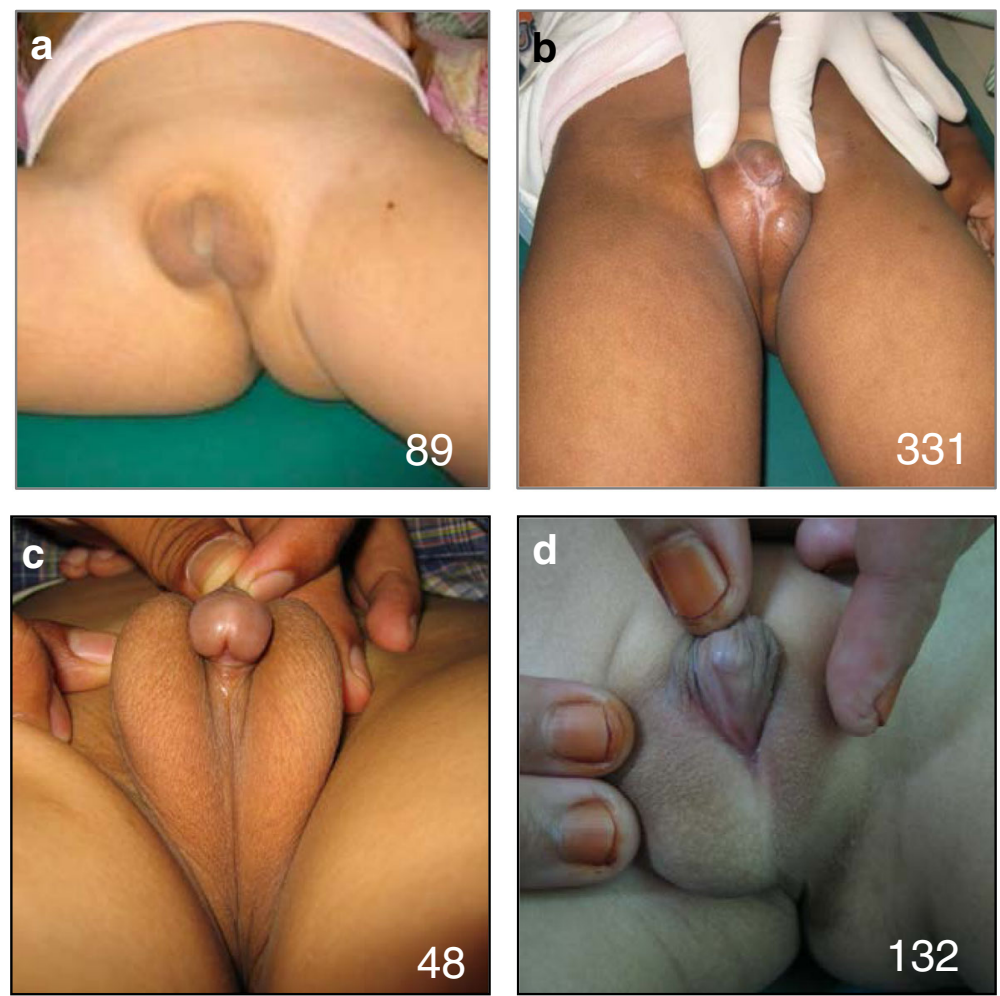

Fig. 1 Under-virilisation in patients with $\mathrm{CHH}$ gene variants. a-d Representative images of external genitalia for four patients presenting with 46,XY DSD (see Table 1 for details)

damaging and highly conserved (Fig. 2c). This was found in patient 163, who has a micropenis and penile hypospadias (Fig. 1, Table 1).

\section{FGFR1}

Three patients had the FGFR1 variant rs140382957 (FGFR1:c.C320T:p.S107L) (Table 2). This variant has a MAF in EVS of 0.0077 and in ExAC of 0.0023 (and while it is predicted to be pathogenic in two prediction tools, one record in ClinVar has it logged as being benign [24].)

\section{CHD7}

Curiously, two of the three patients who had a FGFR1 variant also had a variant in $C H D 7$. One of these, $C H D 7$ : c.G1565T:p.G522V has an ExAC MAF of 0.002318 and was predicted damaging (Table 2); however, it has been reported as benign for CHARGE on ClinVar. This was found in patient 101. Another novel variant was rare $($ ExAC MAF $=9.2 \mathrm{e}-05)$ (CHD7:c.C2347T:p.P783S). No other $C H D 7$ variants were found.

\section{Discussion}

In this study, we have investigated variants in $\mathrm{CHH}$ related genes in a cohort of Indonesian 46,XY DSD patients who had an under-virilisation phenotype. After excluding patients with mutations in known DSD genes, we found rare and damaging variants in $\mathrm{CHH}$ genes in 11 of the remaining 28 patients. $\mathrm{CHH}$ and $\mathrm{KS}$ can present at birth with under-virilisation phenotypes in males such as micropenis and cryptorchidism [25]. Our study suggests that $\mathrm{CHH}$ may be a cause of undervirilisation in Indonesia. While forty-seven 46,XY DSD patients were initially recruited, 19 of these were found to harbour mutation in a known DSD genes such as $A R$ (data not shown). Of the remaining 28 , we found a likely $\mathrm{CHH}$ variant(s) in 11 patients, making this a total of $25 \%$ of the total original cohort. In addition, while our targeted DSD panel has a comprehensive list of diagnostic DSD genes, it only covers 19 of approximately 24 genes that cause $\mathrm{CHH} / \mathrm{KS}$ without an associated syndrome. Sequencing of the entire list of known $\mathrm{CHH}$ genes, including those that cause $\mathrm{CHH}$ in association with additional anomalies, may increase the diagnostic yield of a genetic screen like this. This will be important for future studies of this cohort.

Penile and urethral morphology is established before 14 weeks gestation meaning that the foetal pituitaryhypothalamic axis is typically thought to be unnecessary for normal penile development (instead relying on maternal hCG). However, after week 14, continued increase in penile length is dependent upon the hypothalamic- 


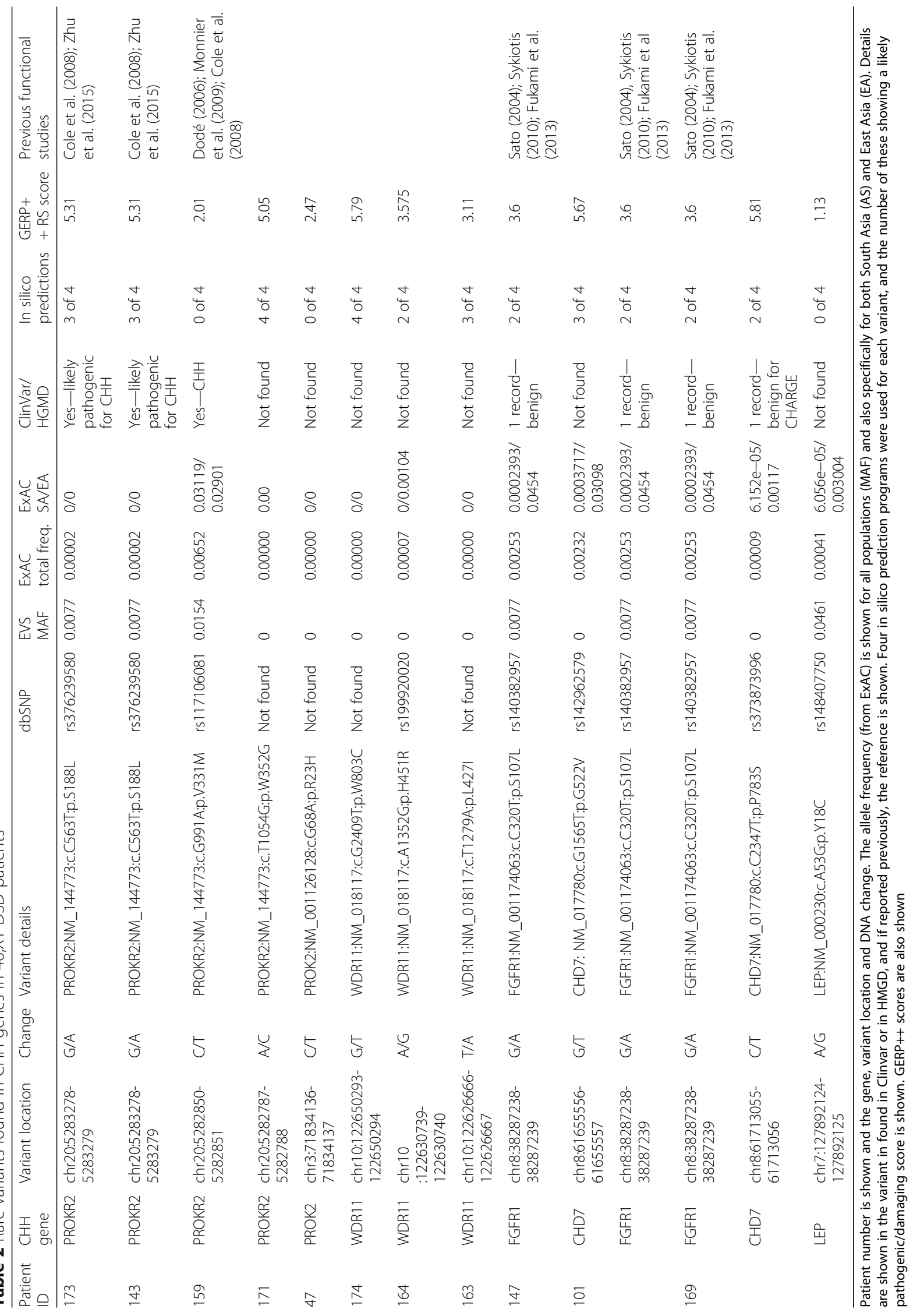




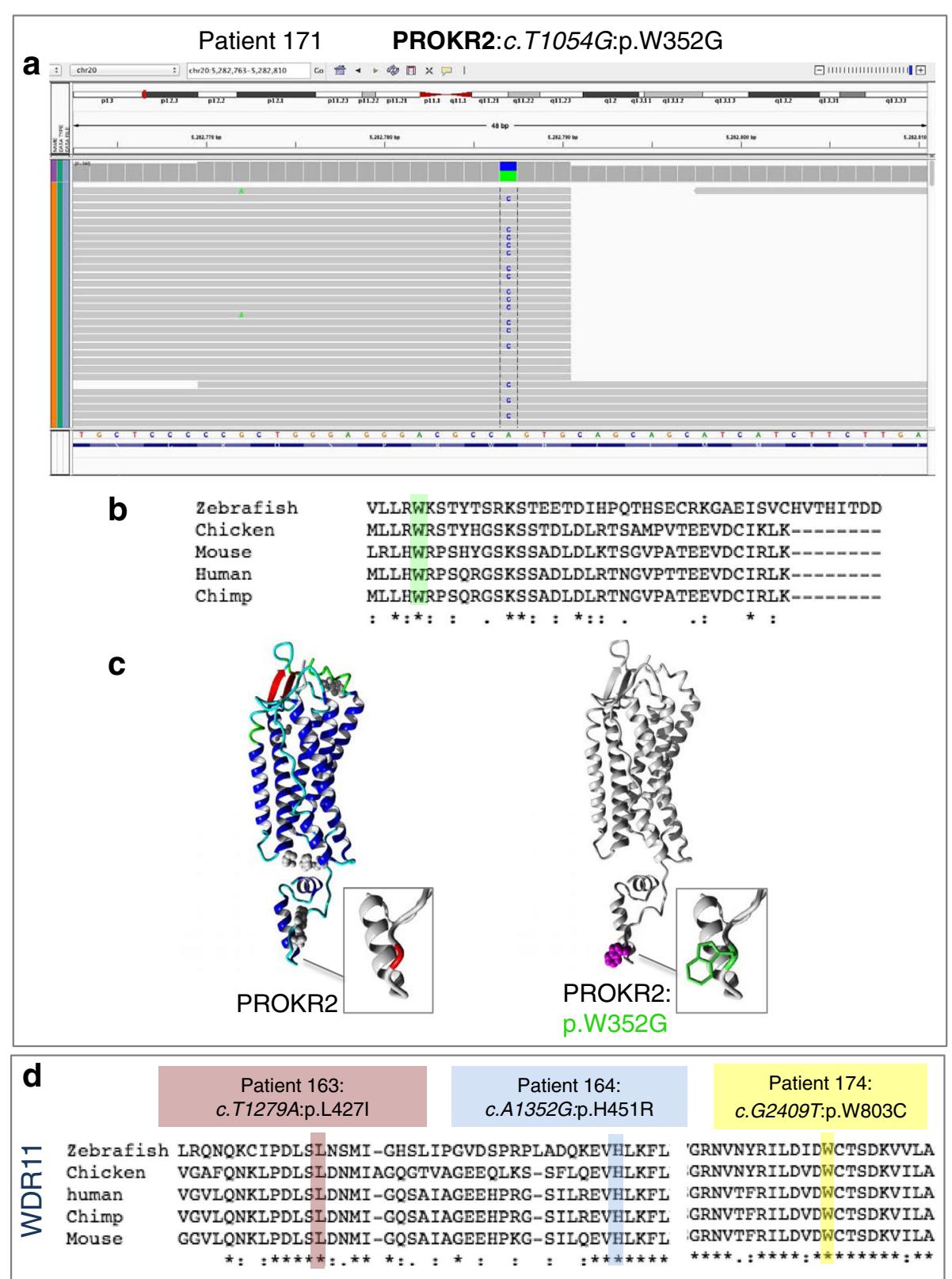

Fig. 2 Novel variants in CHH genes. Just one novel variant in PROKR2 was found (p.W352G). This change found in patient 171, c.T1054G:p.W352G, is heterozygous and has good quality and depth (a). This change falls on a highly conserved residue (b) and lies within the cytoplasmic tail of this transmembrane receptor (c). Three novel variants in WDR11 were found in our cohort—all of which affect a highly conserved residue (d)

pituitary axis. Therefore, boys with hypogonadism will often have micropenis but normal phallic morphology. However, we found that many of individuals in our cohort had varying degrees of hypospadias. Given this, it is interesting to note that while rare, hypospadias in patients with $\mathrm{CHH}$ or $\mathrm{KS}$ has been described. A large study found two patients with $\mathrm{CHH}$ and hypospadias [26], and several other studies have described patients with KS or $\mathrm{CHH}$ and hypospadias of varying degrees [8, 27-29]. Nevertheless, hypospadias in $\mathrm{CHH}$ is a rare combination, and it is interesting to speculate why our cohort has an over-representation of variants in $\mathrm{CHH}$ genes in patients with hypospadias. It is possible that in our cohort of Indonesian patients, $\mathrm{CHH}$ and $\mathrm{KS}$ manifest in a unique way, as we have not found this association in patients with 46,XY DSD of other nationalities (data not shown). Or, it may be that these variants simply contribute to a phenotype in these patients that could involve additional undetected variants in genes controlling either gonadal or penile development. It is 
also possible that these genes/variants have an interaction with environmental cues in this population, resulting in more common under-virilisation in $\mathrm{CHH}$ than in other populations. Indeed, many of the described patients come from low socio-economic communities, and many of them are involved in agriculture. Both genetic and environmental factors are thought to contribute to isolated hypospadias (reviewed in [30]), and numerous studies in different populations have shown agriculture and pesticides to be a risk factor for reproductive development and health, e.g. [31-34]. Finally, it is possible that these variants detected in $\mathrm{CHH}$ genes are non-damaging variants over-represented in the Indonesian population. However, three patients had a PROKR2 variant previously shown to be deleterious in functional studies, and we have sequenced more than 100 individuals from Indonesia (include severe DSD patients, parents and siblings) who were not enriched for these or other rare variants in $\mathrm{CHH}$ genes (data not shown).

Mutations in PROK2 and PROKR2 are thought to contribute to around $9 \%$ of patients with KS [23]. In our cohort, a total of four patients had a variant in PROKR2 and one with PROK2. We also had three patients with WDR11 variants, meaning this gene may also play a significant role in Indonesian 46,XY DSD patients. Overall, we have found eight variants in $\mathrm{CHH}$ genes that have not been previously described in this disorder. Of these, four are not present in online variant databases ExAC or EVS. The PROKR2 variant p.W352G lies within the cytoplasmic tail of this transmembrane receptor. Other variants have been described in this region (such as p.V331M - which we also found, and p.R357W) [21]. In this case, the mutant residue (glycine) is smaller than the wild-type residue and differs in hydrophobicity to the wild-type residue (tryptophan). This may cause a loss of external interactions in particular a loss of hydrophobic interactions with other molecules on the surface of the protein. One patient had a variant in PROK2 (p.R23H) that has not been previously described. The affected amino acid lies within the signal peptide region, and the mutant residue (histidine) is smaller than the wild-type residue and has a different charge (neutral rather than positive). This may change the activity of the signal peptide, and a patient with a variant affecting the neighboring amino acid (p.A24P) has been described previously in $\mathrm{CHH}$ [21].

The PROKR2 p.V331M variant that we and others have found has been shown to have reduced functional activity (albeit weaker than other variants) [21-23]; however, it is not predicted to be damaging by any of the four prediction tools used. This is likely due to the fact that several orthologous proteins in other species have a methionine in this protein position. It has been suggested that filtering variants based on currently available pathogenicity tools may lead to under-reporting of such compensated variants [35]. Therefore, while we have included the in silico predictions of pathogenicity in our pipeline, we have chosen to report all rare variants in this manuscript regardless of these predictions.

Finally, two novel WDR11 variants were found in our screen. WDR11 is predicted to exhibit two $\beta$ propellers made up of WD domains. Protein structure modelling has predicted that WDR11 has 12 WD domains and that nine of them (second through tenth) participate in the genesis of two consecutive $\beta$ propellers [36]. The p.W803C variant in which a tryptophan is replaced by a cysteine at position 803 falls within the 12th WD domain and is a highly conserved amino acid [36]. Cysteine is a smaller residue than the wild-type residue, which could interrupt with the WD function. The p.L427I change is predicted to fall adjacent to WD domain 6, where at least two other human variants have been described [36].

Interestingly, we also found two patients with both FGFR1 and CHD7 variants. Indeed, oligogenicity has been described to be a feature of $\mathrm{CHH}$ (for a summary, see [3]). Specifically, oligogenic inheritance has been previously reported for FGFR1, while no reports for $C H D 7$ oligogenicity have yet been published. While CHD7 has most frequently been associated with CHARGE syndrome, of which hypospadias can be a feature, a recent paper has detailed patients in which CHD7 singlenucleotide variants (SNVs) were not associated with classical CHARGE syndromic features. Indeed, they show that rare deleterious SNVs in this gene contribute to the mutational burden of patients with both KS and $\mathrm{CHH}$ in the absence of full CHARGE syndromic features [37]. It may be that a combination of variant alleles in FGFR1 and CHD7 can cause hypospadias and undervirilisation. However, several of the FGFR1 and CHD7 variants had a total MAF of around $0.2 \%$, with a prevalence of 0.3 or $0.4 \%$ in East Asia indicating that they may be over-represented in the Indonesian population. Further studies to address the pathogenicity of these variants and the interaction between FGFR1 and CHD7 are required and are beyond the scope of this study.

Hormonal analysis at the right age can be highly informative in a clinical diagnosis of $\mathrm{CHH}$. This includes assays of the levels of the gonadotrophins FSH and LH, as well as testosterone levels before and after hCG stimulation. Diagnosis of KS and CHH in many of these patients has been limited by access to detailed blood hormone analysis (in particular as many are prepubescent children meaning that measuring $\mathrm{LH}$ and FSH is not informative). Most of our patients showed low levels of testosterone (consistent with their age), but these levels were stimulated by hCG. Nevertheless, the genetic results of this study suggest that boys presenting 
with under-virilisation phenotypes in Indonesian clinics should be tested for $\mathrm{CHH}$ or KS. The patients presented here will be monitored as they develop, and we recommend they have their gonadotrophin levels retested at a later date when reduced levels can be detected.

A genetic diagnosis can inform family planning and fertility investigations, as well as direct clinical management. Treatments exist for many of the features of $\mathrm{CHH}$. In early life, this can include low-dose testosterone or gonadotrophins for micropenis and stimulation of gonadal development. Later, during adolescence or adulthood, testosterone therapy can also induce puberty including psychosocial development [3]. $\mathrm{CHH}$-associated infertility can also be treated, for example, by administering GnRH or gonadotrophins [3]. Thus, given the therapeutic options, having a genetic diagnosis may allow earlier or tailored intervention. Gene panel testing is a viable option to deliver this genetic diagnosis.

\section{Conclusion}

We conclude that variants in $\mathrm{CHH}$ genes, in particular PROKR2, PROK2, WDR11 and FGFR1 with CHD7, may contribute to under-virilisation phenotypes including hypospadias in Indonesian boys. We suggest that in this population, 46,XY DSD patients should be monitored for signs of $\mathrm{CHH}$ including hormonal and genetic analysis.

\section{Abbreviations}

$\mathrm{CHH}$ : Congenital hypogonadotrophic hypogonadism; DHT: Dihydrotestosterone; DSD: Disorder of sex development; FSH: Follicle-stimulating hormone; GnRH: Gonadotrophin-releasing hormone; hCG: Human chorionic gonadotrophin; KS: Kallmann syndrome; LH: Luteinising hormone

\section{Acknowledgements}

The authors would like to thank the patients who kindly consented to be part of this study.

\section{Funding}

KA, GR and JvdB are funded by a National Health and Medical Research Council (NHMRC) program grant (number APP1074258). AS is funded by a NHMRC research fellowship.

\section{Availability of data and materials}

The raw genetic data from each patient is available publically as stipulated in [17].

\section{Authors' contributions}

$\mathrm{KLA}$ analysed and interpreted the data and wrote the manuscript. $A B$ interpreted the data and critically revised the manuscript. GR and JvdB handled the DNA, carried out sequencing, and analysed data. NAL and AZJ collected and analysed the patient clinical data. AHS and SMHF supervised the work, contributed to the study design and interpretation, and critically reviewed the manuscript. All authors have read and approved the manuscript for publication.

\section{Competing interests}

The authors declare that they have no competing interests.

\section{Consent for publication}

All participants included in this study have given their informed consent for the publication of this manuscript.

\section{Ethics approval and consent to participate}

The medical ethics committee of the Dr. Kariadi Hospital/FMDU approved this study and informed consent was obtained from all participants and or their parents or guardians prior to their participation.

\section{Author details}

${ }^{1}$ Murdoch Childrens Research Institute, Melbourne, Victoria, Australia. ${ }^{2}$ Department of Paediatrics, University of Melbourne, Melbourne, Victoria, Australia. ${ }^{3}$ The Royal Children's Hospital, Melbourne, Victoria, Australia. ${ }^{4}$ Division of Human Genetics, Centre for Biomedical Research, Faculty of Medicine, Diponegoro University (FMDU), JL. Prof. H. Soedarto, SH,

Tembalang, Semarang 50275, Central Java, Indonesia.

Received: 23 December 2016 Accepted: 11 February 2017

Published online: 16 February 2017

\section{References}

1. Walker $\mathrm{WH}$, Cheng J. FSH and testosterone signaling in Sertoli cells. Reproduction. 2005;130:15-28. Society for Reproduction and Fertility.

2. Svechnikov K, Landreh L, Weisser J, Izzo G, Colón E, Svechnikova I, et al. Origin, development and regulation of human Leydig cells. Horm Res Paediatr. 2010:73:93-101.

3. Boehm U, Bouloux P-M, Dattani MT, de Roux N, Dodé C, Dunkel L, et al. Expert consensus document: European Consensus Statement on congenital hypogonadotropic hypogonadism - pathogenesis, diagnosis and treatment. Nat Rev Endocrinol. 2015;11:547-64. Nature Publishing Group.

4. Teixeira L, Guimiot F, Dodé C, Fallet-Bianco C, Millar RP, Delezoide A-L, et al. Defective migration of neuroendocrine $\mathrm{GnRH}$ cells in human arrhinencephalic conditions. The Journal of clinical investigation. Am Soc Clin Invest. 2010;120:3668-72.

5. Schwanzel-Fukuda M, Pfaff DW. Origin of luteinizing hormone-releasing hormone neurons. Nature. 1989;338:161-4. Nature Publishing Group.

6. Bianco SDC, Kaiser UB. The genetic and molecular basis of idiopathic hypogonadotropic hypogonadism. Nat Rev Endocrinol. 2009;5:569-76. Nature Publishing Group.

7. Fraietta R, Zylberstejn DS, Esteves SC. Hypogonadotropic hypogonadism revisited. Clinics (Sao Paulo). Hospital das Clinicas da Faculdade de Medicina da Universidade de Sao Paulo. 2013;68 Suppl 1:81-8.

8. Moriya K, Mitsui T, Tanaka H, Nakamura M, Nonomura K. Long-term outcome of pituitary-gonadal axis and gonadal growth in patients with hypospadias at puberty. J Urol. 2010;184:1610-4.

9. Ediati A, Juniarto AZ, Birnie E, Drop SLS, Faradz SMH, Dessens AB. Body image and sexuality in Indonesian adults with a disorder of sex development (DSD). J Sex Res. 2013;52:15-29.

10. Ediati A, Faradz SMH, Juniarto AZ, van der Ende J, Drop SLS, Dessens AB. Emotional and behavioral problems in late-identified Indonesian patients with disorders of sex development. J Psychosom Res. 2015;79:76-84. Elsevier Inc.

11. Izumi Y, Suzuki E, Kanzaki S, Yatsuga S, Kinjo S, Igarashi M, et al. Genomewide copy number analysis and systematic mutation screening in 58 patients with hypogonadotropic hypogonadism. Fertil Steril. 2014;102: 1130-3

12. Raivio $T$, Sidis $Y$, Plummer $L$, Chen $H, M a ~ J$, Mukherjee $A$, et al. Impaired fibroblast growth factor receptor 1 signaling as a cause of normosmic idiopathic hypogonadotropic hypogonadism. J Clin Endocrinol Metab. 2009:94:4380-90.

13. Miraoui H, Dwyer AA, Sykiotis GP, Plummer L, Chung W, Feng B, et al. Mutations in FGF17, IL17RD, DUSP6, SPRY4, and FLRT3 are identified in individuals with congenital hypogonadotropic hypogonadism. Am J Hum Genet. 2013;92:725-43.

14. Juniarto Z, van der Zwan YG, Santosa A, Ariani MD, Eggers S, Hersmus R, et al. Hormonal evaluation in relation to phenotype and genotype in 286 patients with a disorder of sex development from Indonesia. Clin Endocrinol (Oxf). 2016;n/a-n/a.

15. Soldin OP, Hoffman EG, Waring MA, Soldin SJ. Pediatric reference intervals for FSH, LH, estradiol, T3, free T3, cortisol, and growth hormone on the DPC IMMULITE 1000. Clin Chim Acta. 2005:355:205-10.

16. Miller SA, Dykes DD, Polesky HF. A simple salting out procedure for extracting DNA from human nucleated cells. Nucleic Acids Res. 1988;16: 1215. Oxford University Press. 
17. Eggers S, Sadedin S, van den Bergen JA, Robevska G, Ohnesorg T, Hewitt J, et al. Disorders of sex development: insights from targeted gene sequencing of a large international patient cohort. Genome Biol. 2016;17: 243. BioMed Central.

18. Sadedin SP, Dashnow H, James PA, Bahlo M, Bauer DC, Lonie A, et al. Cpipe: a shared variant detection pipeline designed for diagnostic settings. Genome Med. 2015;7:68

19. Venselaar H, Beek Te TAH, Kuipers RKP, Hekkelman ML, Vriend G. Protein structure analysis of mutations causing inheritable diseases. An e-Science approach with life scientist friendly interfaces. BMC Bioinformatics. 2010;11: 548. BioMed Central.

20. Zhu J, Choa RE-Y, Guo MH, Plummer L, Buck C, Palmert MR, et al. A shared genetic basis for self-limited delayed puberty and idiopathic hypogonadotropic hypogonadism. J Clin Endocrinol Metab. 2015;100: E646-54. Endocrine Society Chevy Chase.

21. Cole LW, Sidis Y, Zhang C, Quinton R, Plummer L, Pignatelli D, et al. Mutations in prokineticin 2 and prokineticin receptor 2 genes in human gonadotrophin-releasing hormone deficiency: molecular genetics and clinical spectrum. J Clin Endocrinol Metab. 2008;93:3551-9.

22. Monnier C, Dodé C, Fabre L, Teixeira L, Labesse G, Pin J-P, et al. PROKR2 missense mutations associated with Kallmann syndrome impair receptor signalling activity. Hum Mol Genet. 2009;18:75-81. Oxford University Press.

23. Dodé C, Rondard P. PROK2/PROKR2 signaling and Kallmann syndrome. Front Endocrinol (Lausanne). 2013;4:19. Frontiers.

24. Fukami M, Iso M, Sato N, Igarashi M, Seo M, Kazukawa I, et al. Submicroscopic deletion involving the fibroblast growth factor receptor 1 gene in a patient with combined pituitary hormone deficiency. Endocr J. 2013;60:1013-20.

25. Costa-Barbosa FA, Balasubramanian R, Keefe KW, Shaw ND, Tassan Al N, Plummer $L$, et al. Prioritizing genetic testing in patients with Kallmann syndrome using clinical phenotypes. J Clin Endocrinol Metab. 2013;98:E943-53.

26. Vizeneux A, Hilfiger A, Bouligand J, Pouillot M, Brailly-Tabard S, Bashamboo A, et al. Congenital hypogonadotropic hypogonadism during childhood: presentation and genetic analyses in 46 boys. Veitia RA, editor. PLoS ONE. 2013;8:e77827. Public Library of Science.

27. Kurzrock EA, Delair S. Hypospadias and Kallmann's syndrome: distinction between morphogenesis and growth of the male phallus. J Pediatr Urol. 2006;2:515-7.

28. Knorr JR, Ragland RL, Brown RS, Gelber N. Kallmann syndrome: MR findings. AJNR Am J Neuroradiol. 1993;14:845-51.

29. Ponticelli C, Frosini P, Masi L. Kallmann's syndrome. Apropos of 2 personal cases. Acta Otorhinolaryngol Ital. 1991;11:603-8.

30. Bouty A, Ayers KL, Pask A, Heloury Y, Sinclair AH. The genetic and environmental factors underlying hypospadias. Sex Dev. 2015;9:239-59. Karger Publishers.

31. Strazzullo M, Matarazzo MR. Epigenetic effects of environmental chemicals on reproductive biology. Curr Drug Targets. 2016.

32. Bianca S, Li Volti G, Caruso-Nicoletti M, Ettore G, Barone P, Lupo L, et al. Elevated incidence of hypospadias in two sicilian towns where exposure to industrial and agricultural pollutants is high. Reprod Toxicol. 2003;17:539-45.

33. Xu L-F, Liang C-Z, Lipianskaya J, Chen X-G, Fan S, Zhang L, et al. Risk factors for hypospadias in China. Asian J Androl. 2014;16:778-81.

34. Kristensen P, Irgens LM, Andersen A, Bye AS, Sundheim L. Birth defects among offspring of Norwegian farmers, 1967-1991. Epidemiology. 1997;8:537-44.

35. Azevedo L, Mort M, Costa AC, Silva RM, Quelhas D, Amorim A, et al. Improving the in silico assessment of pathogenicity for compensated variants. Eur J Hum Genet. 2016;25:2-7.

36. Kim H-G, Ahn J-W, Kurth I, Ullmann R, Kim H-T, Kulharya A, et al. WDR11, a WD protein that interacts with transcription factor EMX1, is mutated in idiopathic hypogonadotropic hypogonadism and Kallmann syndrome. Am J Hum Genet. 2010;87:465-79.

37. Balasubramanian R, Choi J-H, Francescatto L, Willer J, Horton ER Asimacopoulos EP, et al. Functionally compromised CHD7 alleles in patients with isolated $\mathrm{GnRH}$ deficiency. Proceedings of the National Academy of Sciences. National Acad Sci. 2014;111:17953-8.

\section{Submit your next manuscript to BioMed Central and we will help you at every step:}

- We accept pre-submission inquiries

- Our selector tool helps you to find the most relevant journal

- We provide round the clock customer support

- Convenient online submission

- Thorough peer review

- Inclusion in PubMed and all major indexing services

- Maximum visibility for your research

Submit your manuscript at www.biomedcentral.com/submit
Biomed Central 